\title{
Transgenic Rice Plants Expressing an Active Tobacco Mitogen-activated Protein Kinase Kinase Induce Multiple Defense Responses
}

\author{
Jin A Jeong ${ }^{1}$, Seung Jin Yoo ${ }^{1}$, Douck Hee Yang ${ }^{1}$, Seo Ho Shin ${ }^{2}$, Myung Chul Lee ${ }^{3}$, Baik Ho Cho ${ }^{1}$ and \\ Kwang-Yeol Yang ${ }^{*}$ \\ ${ }^{1}$ Agricultural Plant Stress Research Center, Department of Plant Biotechnology, College of Agriculture and Life Sciences, \\ Chonnam National University, Gwangju 500-757, Korea \\ ${ }^{2}$ Department of Rice and Winter Cereal Crop, National Institute of Crop Science, RDA, Iksan 570-080, Korea \\ ${ }^{3}$ National Agrobiodiversity Center, National Academy of Agricultural Science, RDA, Suwon 441-707, Korea \\ (Received on August 12, 2008; Accepted on November 7, 2008)
}

It is well known that NtMEK2, a tobacco MAPK kinase, is the upstream kinase of both salicylic acidinduced protein kinase and wound-induced protein kinase. In addition, expression of $N T M E K 2^{D D}$, a constitutively active mutant of NtMEK2, is known to induce multiple defense responses in tobacco. In this study, transgenic rice plants that contained an active or inactive mutant of NtMEK2 under the control of a steroid inducible promoter were generated and used to determine if a similar MAPK cascade is involved in disease resistance in rice. The expression of $N t M E K 2^{D D}$ in transgenic rice plants resulted in HR-like cell death. The observed cell death was preceded by the activation of endogenous rice $48-\mathrm{kDa}$ MBP kinase, which is also activated by Xanthomonas oryzae pv. oryzae, the bacterial blight pathogen of rice. In addition, prolonged activation of the MAPK induced the generation of hydrogen peroxide and up-regulated the expression of defense-related genes including the pathogenesis-related genes, peroxidases and glutathione S-transferases. These results demonstrate that NtMEK2 is functionally replaceable with rice MAPK kinase in inducing the activation of the downstream MAPK, which in turn induces multiple defense responses in rice.

Keywords : Defense-related genes, hydrogen peroxide, hypersensitive response-like cell death, mitogen-activated protein kinase, Xanthomonas oryzae pv. oryzae

The mitogen-activated protein kinase (MAPK) cascade is a major and evolutionally conserved signaling pathway that transduces extracellular stimuli into intracellular responses in eukaryotic cells (Jonak et al., 2002; Widmann et al., 1999). MAPK cascades are composed of three protein kinase modules, MAPK, MAPK kinase (MAPKK) and MAPKK kinase (MAPKKK). MAPK, the last kinase in the

\footnotetext{
*Corresponding author.

Phone) +82-62-530-2076, FAX) +82-62-530-0207

E-mail)kyyang@chonnam.ac.kr
}

three-kinase cascade, is activated by dual phosphorylation of Thr and Tyr residues in a TXY motif by MAPKK. MAPKK, in turn, is activated by MAPKKK (MAPK Group et al., 2002). Extensive studies conducted by several groups have demonstrated that salicylic acid-induced protein kinase (SIPK) and wound-induced protein kinase (WIPK), which are two well-characterized tobacco MAPKs, as well as their functional orthologs in Arabiopsis, MPK6 and MPK3, are activated in plants in response to biotic or abiotic stresses (Asai et al., 2002; Mishra et al., 2006; Zhang and Klessig, 1998; Zhang and Klessig, 2001). In addition, ectopic expression of a constitutively active mutant of NtMEK2, the upstream kinase of SIPK and WIPK, was recently found to induce HR-like cell death and defense-related gene expression, as well as to promote the generation of $\mathrm{H}_{2} \mathrm{O}_{2}$ in chloroplasts in tobacco (Liu et al., 2007; Yang et al., 2001).

Several studies have been conducted to evaluate the ability of tobacco NtMEK2 and its orthologs in other dicot plants such as Arabidopsis and potato. One study has demonstrated that NtMEK2 was functionally interchangeable with AtMKK4 and AtMKK5, two Arabidopsis orthologs of NtMEK2, for activation of the downstream MAPKs in Arabidopsis (Ren et al., 2002). In addition, a recent study found that a fungal-responsive MAPK cascade, MAPKKK $\alpha /$ MEKK1-MKK4/MKK5-MPK3/MPK6, plays a positive role in regulation of the biosynthesis of camalexin in Arabidopsis (Ren et al., 2008). It has also been reported that StMEK $1{ }^{\text {DD }}$, a constitutively active mutant of the potato ortholog of tobacco NtMEK2, is capable of activating SIPK and WIPK and inducing the accumulation of defense genes in tobacco plants (Katou et al., 2003). Moreover, it has been shown that StMEK $1^{D D}$ transgenic potato plants driven by a pathogen-inducible promoter have resistance to the early blight pathogen, Alternaria solani, as well as to Phytophthora infestans (Yamamizo et al., 2006).

To date, a total of 17 rice MAPK genes have been identified. Of these MAPKs, OsMPK1, OsMPK2, OsMAPK4, 
OsMAPK5, OsMPK7, OsMPK8, OsMPK12, OsMPK13, OSMPK15 and OSMPK17 are induced by the rice blast fungus (Magnaporthe grisea), BTH or defense signal molecules such as salicylic acid (SA), jasmonic acid (JA), ethylene (ET) or $\mathrm{H}_{2} \mathrm{O}_{2}$ at the mRNA level (Lee et al., 2008; Rohila and Yang, 2007). These results suggest that at least 10 rice MAPKs are involved in defense signaling in rice. However, little is known about the entire pathogenresponsive MAPK cascade (MAPKKK-MAPKK-MAPK) in rice. Therefore, further studies are necessary to identify upstream kinases and downstream target proteins to better understand the MAPK-mediated pathways associated with disease resistance in rice.

In this study, we transformed rice plants with the tobacco $N t M E K 2^{D D}$ or $N t M E K 2^{K R}$ gene, which encodes the constitutively active mutant or the inactive mutant of NtMEK2, respectively, to understand the MAPK cascade associated with defense responses in rice, an economically valuable monocot plant. In $N t M E K 2^{D D}$ transgenic rice, activation of mainly endogenous rice $48-\mathrm{kDa}$ myelin basic protein (MBP) kinase was found to lead to HR-like cell death, which was preceded by the generation of hydrogen peroxide. Furthermore, expression of the $N t M E K 2^{D D}$ gene in transgenic rice plants induced the expression of several defense-related genes.

\section{Materials and Methods}

Generation of transgenic rice plants. The $N t M E K 2^{D D}$ and $N t M E K 2^{K R}$ constructs were used to generate transgenic rice (Yang et al., 2001). Each construct was transformed into Agrobacterium tumefaciens EHA105 by electroporation using a cell-porator according to the manufacturer's instructions (Life Technologies, Rockville, USA). Rice transformation was then conducted using the protocol described by Hiei et al. (1994) with slight modifications (Lee et al., 2002). Briefly, calli from the mature embryos (Oryza sativa
L. cv. Dongiin) were co-cultured with A. tumefaciens EHA105 that harbored a constitutively active mutant or inactive mutant of the NtMEK2 gene for 3 days. Next, the calli were washed 10 times in distilled water and then placed on pre-selection medium for 10 days. Several calli were then selected for additional growth on MS medium containing $50 \mathrm{mg} / \mathrm{L}$ hygromycin and $250 \mathrm{mg} / \mathrm{L}$ carbenicillin for 1 month. The calli were then regenerated on shooting medium for 2 months, after which they were transferred to rooting MS medium containing antibiotics for 2 weeks. For regeneration, the temperature of the tissue culture room was maintained at $25^{\circ} \mathrm{C}$ with a $16 \mathrm{~h} \operatorname{light} / 8 \mathrm{~h}$ dark photoperiod. The regenerated transgenic plants were then moved into soil and maintained in a greenhouse until seed harvest (Fig. 1). Next, the $T_{1}$ seeds of the transformants were selected on MS medium containing $50 \mathrm{mg} / \mathrm{L}$ hygromycin and used for the following experiments after being moved into soil.

Inoculation with the rice bacterial pathogen. Xanthomonas oryzae pv. oryzae (Xoo) strain K3 inoculum was used after suspending bacteria grown in NB (Nutrient broth, $5 \mathrm{~g}$ peptone, $5 \mathrm{~g} \mathrm{NaCl}, 2 \mathrm{~g}$ Yeast extract, $1 \mathrm{~g}$ Beef extract per 1 liter) in $10 \mathrm{mM} \mathrm{MgCl}_{2}$ buffer. Plant inoculation was performed using the leaf clip method. Briefly, the uppermost leaf of the rice plants were cut at the tip $(1-2 \mathrm{~cm})$ with scissors that had been dipped into bacterial inoculums ( $\mathrm{OD}_{600}$ of 1) (Kauffman et al., 1973). The Xoo-infected leaves were then collected at $48 \mathrm{~h}$ after inoculation. Woundtreated leaves were also collected as a control at the same time as the infected leaves.

Preparation of protein extracts and immunoblot analysis. Total protein was extracted from rice leaf tissue by grinding the leaves with small plastic pestles in extraction buffer. The samples were then centrifuged at $18,000 \mathrm{~g}$ for $40 \mathrm{~min}$, after which the supernatants were transferred into
(A)

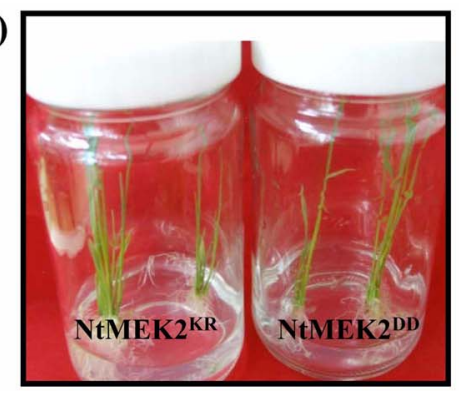

(B)

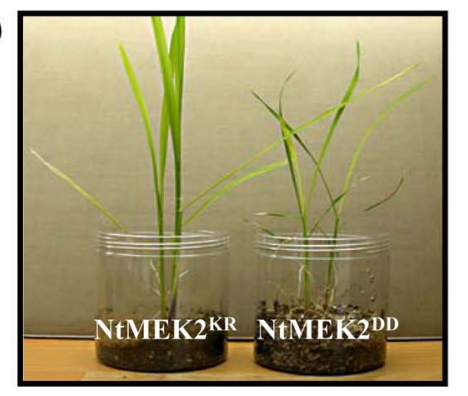

(C)

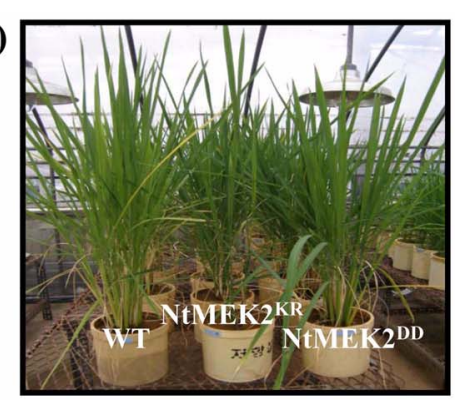

Fig. 1. Construction of $N t M E K 2$ transgenic rice plants. Transgenic rice plants that harbored either an inactive mutant $\left(N t M E K 2^{K R}\right)$ or constitutively active mutant $\left(N t M E K 2^{D D}\right)$ of the $N t M E K 2$ gene were generated. (A) The putative transgenic shoots were transferred to rooting MS medium containing appropriate antibiotics. (B) Transgenic plants were then cultivated in plastic pots for 3 weeks to induce hardening. (C) The hardened transgenic plants were then transferred to pots. Wild type (Oryza sativa $\mathrm{L}$. cv. Dongjin), $\mathrm{T}_{0}$ NtMEK2 ${ }^{K R}$ transgenic rice plants and $\mathrm{T}_{0} N t M E K 2^{D D}$ transgenic rice plants were grown in the greenhouse. 
clean tubes, quickly frozen in liquid nitrogen and then stored at $-80^{\circ} \mathrm{C}$ until analyzed. The concentrations of the protein extracts were determined using a Bio-Rad protein assay kit. Immunoblot analysis of Flag-tagged proteins was then conducted as described previously (Yang et al., 2001). Prestained size markers (Bioneer, Daejeon, KOREA) were used to calculate the size of the kinases.

In-gel kinase activity assay. An in-gel kinase activity assay was performed using previously described methods (Yang et al., 2001). Briefly, $15 \mu \mathrm{g}$ of protein extracts were electrophoresed on $10 \%$ SDS-polyacrylamide gels embedded with $0.1 \mathrm{mg} / \mathrm{ml}$ myelin basic protein in separating gel as a substrate for the kinases. After electrophoresis, the SDS was removed from the gel by washing with washing buffer ( $25 \mathrm{mM}$ Tris- $\mathrm{HCl}, \mathrm{pH}$ 7.5, $0.5 \mathrm{mM}$ dithiothreitol, $0.1 \mathrm{mM}$ $\mathrm{Na}_{3} \mathrm{VO}_{4}, 5 \mathrm{mM} \mathrm{NaF}, 0.5 \mathrm{mg} / \mathrm{ml}$ bovine serum albumin and $0.1 \%$ Triton X-100) three times for $30 \mathrm{~min}$ each at room temperature. The proteins were then renatured in buffer $(25$ $\mathrm{mM}$ Tris-HCl, $\mathrm{pH}$ 7.5, $1 \mathrm{mM}$ dithiothreitol, $0.1 \mathrm{mM} \mathrm{Na}_{3} \mathrm{VO}_{4}$ and $5 \mathrm{mM} \mathrm{NaF}$ ) at $4^{\circ} \mathrm{C}$ overnight with three changes of buffer. The gel was then incubated in $100 \mathrm{ml}$ of reaction buffer (25 mM Tris-HCl, pH 7.5, 2 mM EGTA, $12 \mathrm{mM}$ $\mathrm{MgCl}_{2}, 1 \mathrm{mM}$ dithiothreitol and $0.1 \mathrm{mM} \mathrm{Na}_{3} \mathrm{VO}_{4}$ ) at room temperature for $30 \mathrm{~min}$. Next, phosphorylation was performed for $1.5 \mathrm{~h}$ at room temperature in $30 \mathrm{ml}$ of the same reaction buffer that contained $200 \mathrm{nM}$ ATP plus $50 \mathrm{Ci}$ of $[\gamma$ $\left.{ }^{32} \mathrm{P}\right]$ ATP $(3000 \mathrm{Ci} / \mathrm{mmol})$. The reaction was then stopped by transferring the gel into a solution that contained 5\% trichloroacetic acid (w/v) and $1 \%$ sodium pyrophosphate $(w / v)$. The unincorporated radioactivity was subsequently removed by washing the gel for $6 \mathrm{~h}$ at room temperature, with five changes. The gel was then dried on 3MM paper and subjected to autoradiography. Prestained size markers were used to calculate the size of the kinases.

Histochemical detection of hydrogen peroxide. The pro- duction of hydrogen peroxide was detected by the in situ histochemical staining procedure using 3,3'-diaminobenzidine (DAB) solution (Thordal-Christensen et al., 1997). Briefly, the detached 8-week-old rice leaves that had been treated with DEX were placed in a solution containing 1 $\mathrm{mg} / \mathrm{ml} \mathrm{DAB} \mathrm{(pH} \mathrm{4.2)} \mathrm{for} 8 \mathrm{~h}$. The leaves were then boiled in ethanol (96\%) for $20 \mathrm{~min}$ to remove the chlorophyll.

Reverse transcription-polymerase chain reaction (RTPCR). The expression of defense-related genes was analyzed by extracting RNA from $N t M E K 2^{D D}$ and $N t M E K 2^{K R}$ transgenic rice leaves that had been treated with $100 \mu \mathrm{M}$ DEX using RNeasy plant mini kit. Following DNase treatment, reverse transcription was performed for $1.5 \mathrm{~h}$ at $42^{\circ} \mathrm{C}$ in a reaction mixture with a final volume of $20 \mu$ that contained $3 \mu \mathrm{g}$ of the purified total RNA. The first-strand was then used as a template for PCR amplification, which was conducted using 12.5 pmol of each primer set (Table 1). Next, the RT-PCR products were separated by gel electrophoresis in agarose gel and the bands were then visualized by staining with ethidium bromide.

ACP (annealing control primer)-based differential display RT-PCR. Differentially expressed genes were screened for using GeneFishing ${ }^{\mathrm{TM}}$ DEG kits according to the manufacturer's instructions (Seegene, Seoul, KOREA; Kim et al., 2004). Total RNA was isolated from $N t M E K 2^{K R}-6$ and $N t M E K 2^{D D}-13$ transgenic rice plants collected following DEX treatment. Briefly, reverse transcription was performed for $1.5 \mathrm{~h}$ at $42^{\circ} \mathrm{C}$ in a reaction mixture with a final volume of $20 \mu \mathrm{l}$ that contained $10 \mu \mathrm{M}$ dT-ACP1 and $3 \mu \mathrm{g}$ of the purified total RNA. First-stage PCR for secondstrand cDNA synthesis was conducted in a mixture with a final reaction volume of $50 \mu \mathrm{l}$ that contained the following: 3-5 $\mu \mathrm{l}$ (approximately $50 \mathrm{ng}$ ) of diluted first-strand cDNA, $1 \mu \mathrm{l}$ of dT-ACP $2(10 \mu \mathrm{M}), 1 \mathrm{ul}$ of $10 \mu \mathrm{M}$ arbitrary ACP and $10 \mu 1$ of $2 \times$ Master Mix (Seegene, Seoul, Korea). The PCR

Table 1. Gene specific primer pairs used for RT-PCR

\begin{tabular}{cll}
\hline \hline Gene & \multicolumn{1}{c}{ Forward primer $\left(5^{\prime}-3^{\prime}\right)$} & \multicolumn{1}{c}{ Reverse primer $\left(5^{\prime}-3^{\prime}\right)$} \\
\hline$P R-1 a$ & TCGAGCAGGTTATCCTGCTGCTTG & GAGTAGTTGCAGGTGATGAAGACG \\
$P R-3$ & TACTGTGTCCAGAGCTCGCAGTGG & TCTGGTTGTAGCAGTCCAAGTTGG \\
$P R-5$ & ACCTCTTCCGCTGTCCTC & GAAGACGACTTGGTAGTTGC \\
$P B Z 1$ & GGTGTGGGAAGCACATACAAGAC & AGCTCGTACTCCACCTTG \\
$P O X 2$ & AGGGACAGGCTCTACAACGA & AGTTCCTGACCGTGTTGT \\
$P O X 3$ & GGTGAGAGGGTACGAAG & ATTT GCCACCAGACCATC \\
$P A L$ & AGGTCAACTCCGTGAACGAC & AGGTCAGCCCGTTGTGTAG \\
$G S T T U 4$ & GGTGGTCGAGTTCGCTAAGA & CCAACAAGCACATTAGTTCTCC \\
$G S T T U 12$ & GAGGTGGACAAGCTGATCG & CCACCCCTTCATTCAACATT \\
$C Y P 71 D 7$ & CGATGGAATGTTGCACAAAG & CGCGAAGACCCCATATCTAA \\
$18 s R N A$ & ATGATAACTCGACGGATCGC & CTTGGATGTGGTAGCCGTTT \\
\hline
\end{tabular}


conditions for second-strand synthesis were as follows: one cycle at $94^{\circ} \mathrm{C}$ for $5 \mathrm{~min}$, followed by $50^{\circ} \mathrm{C}$ for $3 \mathrm{~min}$ and $72^{\circ} \mathrm{C}$ for $1 \mathrm{~min}$. After second-strand DNA synthesis was completed, the following protocol was used for the secondstage PCR amplification: 40 cycles of $94^{\circ} \mathrm{C}$ for $40 \mathrm{~s}, 65^{\circ} \mathrm{C}$ for $40 \mathrm{~s}, 72^{\circ} \mathrm{C}$ for $40 \mathrm{~s}$, and a $5 \mathrm{~min}$ final extension at $72^{\circ} \mathrm{C}$. The amplified PCR products were then separated by electrophoreses in a $2 \%$ agarose gel, stained with ethidium bromide and cloned into a pGEM-T Easy cloning vector. The cloned plasmids were then sequenced.

\section{Results and Discussion}

Generation of $\mathbf{N T M E K} 2$ transgenic rice plants and expression of transgene. Transgenic rice plants that contained a constitutively active mutant $\left(N t M E K 2^{D D}\right)$ or an inactive mutant $\left(N t M E K 2^{K R}\right)$ of the $N t M E K 2$ gene under the control of a glucocorticoid-inducible promoter were generated and then examined to determine whether tobacco MAPK kinase was functionally replaceable with rice MAPK kinase. Although the glucocorticoid-inducible system has been characterized extensively in dicot plants, it has not been tested extensively in rice or other monocots. However, Ouwerkerk et al. (2001) did adapt the glucocorticoidinducible system for specific use in rice. In the present study, a Flag tag was added to the N-terminus of the transgene to enable detection of transgene expression using an anti-Flag antibody. The integration of the transgene into putative $\mathrm{T}_{0}$ transgenic plants was detected through polymerase chain reaction using NtMEK2 specific primers (data not shown). The expression of the transgene in $\mathrm{T}_{0}$ transgenic plants was tested by treating detached leaves with DEX (100 $\mu \mathrm{M}$ in water). Briefly, detached 10 -week-old rice leaves were placed in conical tubes that contained DEX in water. The tubes were then sealed with parafilm to prevent dehydration and the leaves were allowed to soak for $24 \mathrm{~h}$. Leaf discs were then collected and the transgene expression

Table 2. Correlation between the inducibility of $N t M E K 2^{D D}$ expression and $\mathrm{HR}$-like cell death in $\mathrm{T}_{0}$ transgenic rice plants

\begin{tabular}{lccc}
\hline \hline Construct & $\begin{array}{c}\text { Total trans- } \\
\text { genic lines }^{\text {generated }}{ }^{\mathrm{a}}\end{array}$ & $\begin{array}{c}\text { Lines showed } \\
\text { transgene }_{\text {inducibility }^{\mathrm{b}}}\end{array}$ & $\begin{array}{c}\text { Lines showed } \\
\text { HR-like cell } \\
\text { death }^{\mathrm{c}}\end{array}$ \\
\hline$N t M E K 2^{D D}$ & 13 & 9 & 9 \\
$N t M E K 2^{K R}$ & 8 & 6 & 0
\end{tabular}

a Transgenic rice plants were generated by Agrobacterium-mediated transformation and selected on MS medium containing hygromycin.

${ }^{\mathrm{b}}$ Transgene inducibility was detected in leaves collected $24 \mathrm{~h}$ after $\operatorname{DEX}(100 \mu \mathrm{M})$ treatment by an immunoblot analysis and an in-gel kinase assay.

${ }^{\mathrm{c}} \mathrm{HR}$-like cell death phenotype was determined between $48 \mathrm{~h}$ and $72 \mathrm{~h}$ after DEX treatment of detached rice leaves. Detached leaves were treated by soaking them in water containing DEX. was checked by immunoblot analysis and an in-gel kinase assay. The HR-like cell death phenotype was then determined between $48 \mathrm{~h}$ and $72 \mathrm{~h}$ following DEX treatment. As shown in Table 2, transgene induction was detected in 9 out of $13 N t M E K 2^{D D}$ lines and 6 out of $8 N t M E K 2^{K R}$ lines following DEX treatment. In addition, only the $N t M E K 2^{D D}$ lines with detectable transgene expression were found to have the HR-like cell death phenotype. Furthermore, no cell death phenotype was observed in transgenic lines that contained the $N t M E K 2^{K R}$ gene, even when transgene expression was detected. Most of the transgenic plants showed a normal growth rate (Fig. 1C). Transgenic $\mathrm{T}_{1}$ seeds were selected by hygromycin resistance. Finally, 3 independent $\mathrm{T}_{1} N t M E K 2^{D D}$ transgenic plants $\left(N t M E K 2^{D D}-5, N t M E K 2^{D D}\right.$ 10, and $\left.N t M E K 2^{D D}-13\right)$ and 2 independent $\mathrm{T}_{1} N t M E K 2^{K R}$ transgenic plants $\left(N t M E K 2^{K R}-3\right.$ and $\left.N t M E K 2^{K R}-6\right)$ were selected at random for further analysis.

Expression of $N t M E K 2^{D D}$ activates endogenous rice 48kDa MBP kinase. The selected 8-week-old $\mathrm{T}_{1}$ plants were collected $24 \mathrm{~h}$ after DEX treatment $(100 \mu \mathrm{M})$. The transgene expression was then evaluated by immunoblot analysis and the activation of endogenous MAPK(s) was evaluated using an in-gel kinase assay. Transgene expression was detected at the protein level in two $\mathrm{T}_{1} N t M E K 2^{K R}$ and three $\mathrm{T}_{1} N t M E K 2^{D D}$ transgenic rice plants. Interestingly, $\mathrm{NtMEK} 2^{\mathrm{DD}}$ proteins were found to be up-shifted in the SDS-PAGE when compared with the NtMEK2 ${ }^{\mathrm{KR}}$ proteins (Fig. 2A and C). Additionally, the activation of an endogenous $48-\mathrm{kDa}$ MBP kinase was observed in all three $\mathrm{T}_{1} N t M E K 2^{D D}$ transgenic rice. Conversely, no endogenous 48-kDa MBP kinase activation was observed in the $\mathrm{T}_{1} N t M E K 2^{K R}$ transgenic rice (Fig. 2B and C). The molecular mass of the $48-\mathrm{kDa}$ MBP kinase in the $\mathrm{T}_{1} N t M E K 2^{D D}$ transgenic rice was calculated by simultaneously conducting SDS-PAGE using proteins extracted from $N t M E K 2^{D D}$ transgenic tobacco plants following DEX treatment $(30 \mu \mathrm{M})$ (data not shown, Jin et al., 2003). To determine if the rice $48-\mathrm{kDa}$ MBP kinase activated by the expression of $N t M E K 2^{D D}$ was involved in the defense responses of rice, proteins from bacterial pathogentreated rice leaves were extracted and analyzed using an ingel kinase assay. Activation of the same $48-\mathrm{kDa}$ MBP kinase was also observed in rice leaves that were treated with $X o o$, the bacterial blight pathogen of rice, whereas no endogenous 48-kDa MBP kinase activation was observed in wound-treated leaves that were used as a control (Fig. 2B, data not shown).

A detailed time-course study of transgenic lines following DEX treatment was performed. Immunoblot analysis revealed that the expression of the transgene in both the $N t M E K 2^{K R}-6$ and the NtMEK $2^{D D}-13$ line occurred after $12 \mathrm{~h}$ of DEX treatment and was maintained for $48 \mathrm{~h}$ after DEX 
(A)

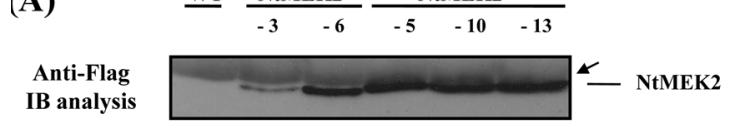

(B)

In-gel kinase
assay

$$
\frac{\text { WT }}{- \text { NtMEK2 }^{K R}} \frac{\text { NtMEK2 }^{\text {DD }}}{-3 \quad-6} \frac{\text { Xoo }}{-5 \quad-10-13}
$$

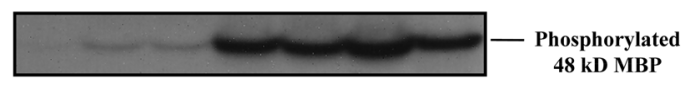

(C)

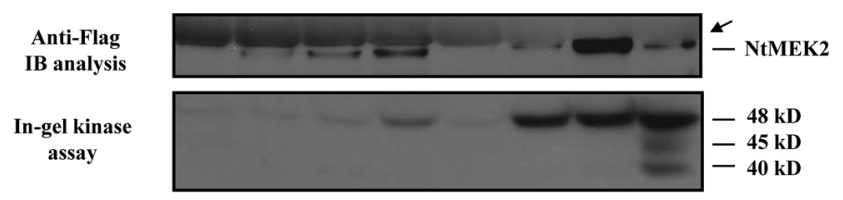

Fig. 2. Expression of $N t M E K 2^{D D}$ activates endogenous rice 48kDa MBP kinase following DEX treatment in $N t M E K 2^{D D}$ transgenic rice plants. Detached leaves from the $T_{1}$ transgenic rice plants, the $N t M E K 2^{K R}{ }_{-3},-6$ lines and the $N t M E K 2^{D D}-5,-10$, and -13 lines as well as a wild type (Oryza sativa L. cv. Dongjin) were treated with DEX $(100 \mu \mathrm{M})$. (A) $\mathrm{T}_{1} N t M E K 2^{K R}$ and NtMEK2 $2^{D D}$ transgenic rice were collected $24 \mathrm{~h}$ after DEX treatment and transgene expression was then determined by immunoblot analysis using anti-Flag antibody. Arrows indicate the rubisco subunit as the background. (B) The activation of endogenous 48-kDa MBP kinase in $\mathrm{T}_{1} N t M E K 2^{D D}$ transgenic rice plants was determined by an in-gel kinase assay using MBP as a substrate. Protein extracts from Xoo-infected rice leaves were also collected and analyzed by an in-gel kinase assay. (C) A detailed time-course analysis was performed. Detached leaves from the $\mathrm{T}_{1}$ transgenic rice plants, the $N t M E K 2^{K R}$-6 line and the $N t M E K 2^{D D}$ - 13 line were treated with DEX were collected during the indicated time period and protein extracts were prepared. Transgene expression was then determined by immunoblot analysis and an in-gel kinase assay. Arrows indicate that the rubisco subunit was the background. All experiments were repeated three times with similar results.

treatment. However, rice 48-kDa MBP kinase activation occurred only in the $N t M E K 2^{D D}-13$ line. In addition, HRlike cell death already began to appear $48 \mathrm{~h}$ after the induction of NtMEK2 $2^{\mathrm{DD}}$ expression in NtMEK2 $2^{D D}-13$ line, at which time the activation of a $45-\mathrm{kDa}$ and a $40-\mathrm{kDa}$ MBP kinase was also detected (Fig. 2C). This result indicates that long-lasting activation of the $48-\mathrm{kDa}$ MBP kinase is sufficient to induce HR-like cell death, and that other MBP kinases may play a role in accelerating the cell death process. This data is consistent with the results of a study conducted by Zhang and Liu (2001) in which SIPK alone was found to be sufficient for the activation of several defense responses, including HR-like cell death. However, the cell death phenotype is delayed in the absence of WIPK activity. Furthermore, the extensive research on interaction between SIPK and WIPK demonstrated that the coexpression of WIPK with the active mutant of NtMEK2 resulted in high-level activation of WIPK, which leads to accelerated HR-like cell death in tobacco (Liu et al., 2003). In a previous study, the mRNA level of OsMAPK6 (also known as OsMPKl) and the OsMAPK6 protein level remained constant in response to treatment with a sphingolipid elicitor, however, rapid induction of the kinase activity, which was found to have a molecular mass of 48$\mathrm{kD}$ in the activation assay, was observed in a rice cell culture (Lieberherr et al., 2005). Therefore, we conducted quantitative RT-PCR analysis using primers specific for the OsMAPK6 gene. The mRNA level of OsMAPK6 was not changed in the $N t M E K 2^{K R}{ }_{-} 6$ and the $N t M E K 2^{D D}-13$ line after DEX treatment, whereas the mRNA level of other rice MAPKs was significantly induced in the $N t M E K 2^{D D}$ transgenic rice lines (Data not shown). Taken together, these results suggest that NtMEK2, a tobacco MAPK kinase, activates mainly endogenous $48-\mathrm{kDa}$ MBP kinase in stably transformed rice. This $48-\mathrm{kDa}$ MBP kinase, which might be OsMAPK6, is involved in pathogen infection and defense responses in rice.

Expression of $N t M E K 2^{D D}$ induces HR- like cell death associated with hydrogen peroxide production. The relationship between the expression of the active mutant and HR-like cell death in $\mathrm{T}_{1}$ plants was evaluated. Although the transgenes were expressed in both $N t M E K 2^{D D}$ and $N t M E K 2^{K R}$ transgenic rice, the activation of endogenous 48kDa MBP kinase and HR-like cell death was only observed in the $N t M E K 2^{D D}$ transgenic plants. Interestingly, we found black speckled lesions in the $N t M E K 2^{D D}$ lines within $40 \mathrm{~h}$ of DEX treatment, prior to the HR-like cell death, and dehydration of the tissue was eventually observed in the plants (Fig. 3A and B). To determine if $\mathrm{H}_{2} \mathrm{O}_{2}$ production is involved in the HR-like cell death induced by activation of the endogenous $48-\mathrm{kDa}$ MBP kinase pathway in $N t M E K 2^{D D}$ transgenic rice, DAB (3,3'-diaminobenzidine) staining was performed. The results of the staining revealed that $\mathrm{H}_{2} \mathrm{O}_{2}$ generation occurred in $N t M E K 2^{D D}$ transgenic rice plants that had been treated with DEX (Fig. 3C). However, no $\mathrm{H}_{2} \mathrm{O}_{2}$ generation was observed in transgenic rice plants that expressed $N t M E K 2^{K R}$. In addition, the expression of antioxidant genes such as peroxidase and glutathione S-transferase was only significantly increased in the $N t M E K 2^{D D}$ transgenic rice (Fig. 4). Transgenic rice plants expressing a fungal glucose oxidase gene $(G O X)$ lead to increase in the endogenous levels of $\mathrm{H}_{2} \mathrm{O}_{2}$, which in turn caused cell death. In addition, elevated levels of $\mathrm{H}_{2} \mathrm{O}_{2}$ in $G O X$ transgenic rice plants activated the expression of several defense genes and enhanced resistance to bacterial and fungal pathogens (Kachroo et al., 2003). Taken together, these findings indicate that the DAB-detectable $\mathrm{H}_{2} \mathrm{O}_{2}$ production is a late event associated with activation of rice $48-\mathrm{kDa}$ MBP kinase, 

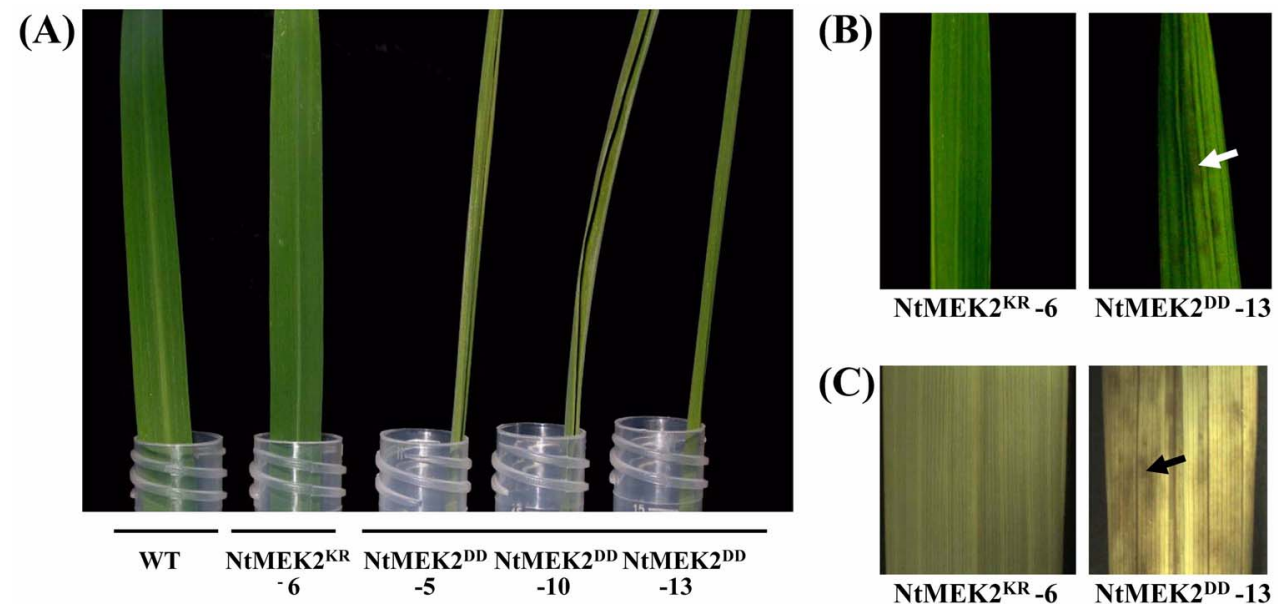

Fig. 3. Hydrogen peroxide production is associated with HR-like cell death induced by NtMEK $2^{\mathrm{DD}}$ in transgenic rice plants. Detached leaves from the $\mathrm{T}_{1}$ transgenic rice plants, the $N t M E K 2^{K R}-6$ line and the $N t M E K 2^{D D}-5,-10$, and -13 lines as well as a wild type (Oryza sativa L. cv. Dongjin, used as a control) were treated with DEX $(100 \mu \mathrm{M})$. (A) Dehydration of the tissues was only observed in the NtMEK2 ${ }^{D D}$ transgenic rice plants that were treated with DEX. The photo was taken $80 \mathrm{~h}$ after DEX treatment. (B) The black speckled lesions were observed in the $N t M E K 2^{D D}$ transgenic rice plants (arrowed). (C) $\mathrm{H}_{2} \mathrm{O}_{2}$ production was detected by immersing the leaves in DAB solution $(1 \mathrm{mg} / \mathrm{ml}, \mathrm{pH} 4.2)$ for $8 \mathrm{~h}$, followed by boiling the leaves in ethanol (96\%) for $20 \mathrm{~min}$ to remove the chlorophyll. $\mathrm{H}_{2} \mathrm{O}_{2}$ production was observed (as indicated by formation of a dark brown color) only in the $N t M E K 2^{D D}$ transgenic plants (arrowed). The photo was taken $40 \mathrm{~h}$ after DEX treatment. All experiments were repeated four times with similar results in both the $\mathrm{T}_{0}$ and $\mathrm{T}_{1}$ transgenic lines.

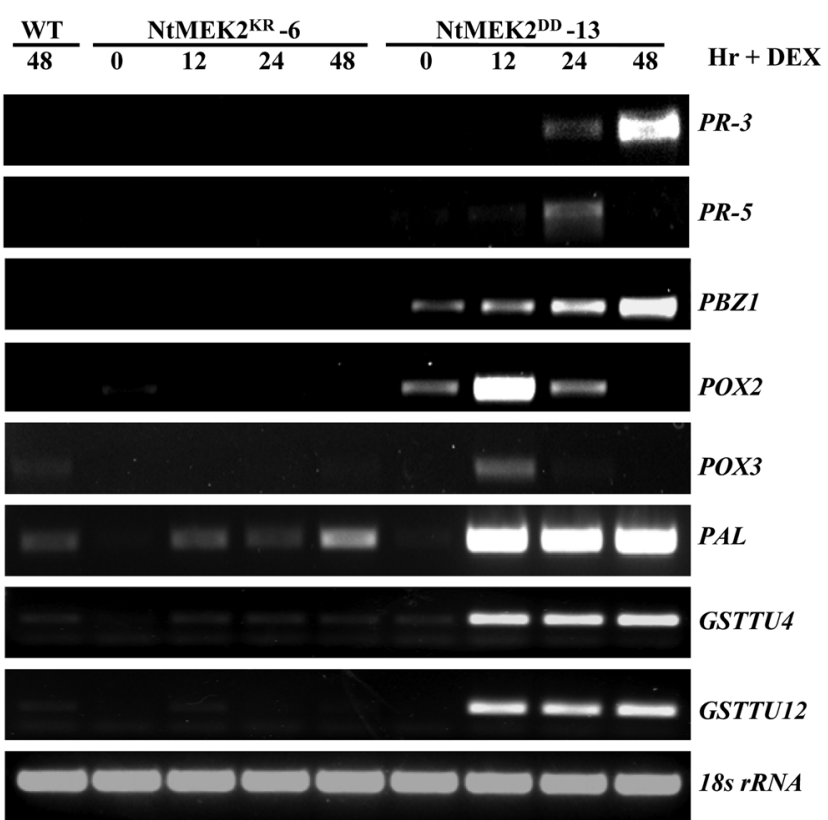

Fig. 4. Induction of $N t M E K 2^{D D}$ expression leads to the activation of several groups of defense genes. Total RNA was isolated from samples from $N t M E K 2^{K R}-6$ and $N t M E K 2^{D D}-13$ transgenic rice collected at the indicated times following DEX treatment. Reverse transcription-PCR analysis was conducted to evaluate the expression of defense-related genes using primers specific for the genes. The bottom gels show reverse transcription-PCR of the housekeeping gene, $18 s \operatorname{rRNA}$, which was used as a loading control. The amplified cDNA products were separated on $1.5 \%$ agarose gels and stained with EtBr. The experiment was repeated three times with similar results. which may contribute directly to the HR-like cell death process.

Effect of NtMEK2 ${ }^{\mathrm{DD}}$ on the expression of defense-related genes. The expression of defense-related genes was confirmed by comparing the $N t M E K 2^{D D}-13$ transgenic line to the $N t M E K 2^{K R}$-6 transgenic line using RT-PCR (Fig. 4). Expression of defense-related genes, including pathogenesis-related $(P R)$ genes and $P B Z 1$ (encodes probenazolinducible protein), $P O X$ genes (encodes peroxidase that plays a role in oxygen metabolism), the $P A L$ gene (encodes phenylalanine ammonia lyase, a key enzyme involved in the production of phytoalexin) and GST genes (encodes glutathione S-transferase, an enzyme involved in cellular detoxification) were induced in the $N t M E K 2^{D D}-13$ transgenic line. As shown in Fig. 4, the PBZ1, PAL and GST genes (GSTTU4 and GSTTU12) were highly induced in the $N t M E K 2^{D D}$ transgenic plant within $12 \mathrm{~h}$ of treatment with DEX. In addition, high levels of $P O X 2$ and $P R-3$ were observed $12 \mathrm{~h}$ and $48 \mathrm{~h}$ after DEX treatment, respectively. However, much lower levels of $P R-5$ and $P O X 3$ were induced in response to treatment when compared to other genes (Fig. 4). Defense-related genes evaluated in this study, which included peroxidase, glutathione S-transferase and PAL, were also up-regulated in rice infected with the bacterial leaf blight pathogen, Хoo. In addition, induction of the ROS scavenging system and glutathione-mediated detoxification may be responsible for hypersensitive cell death in the resistant cultivar upon bacterial infection (Kottapalli et al., 2007). These results indicate that the 
expression of $N t M E K 2^{D D}$ in transgenic rice leads to the activation of several groups of defense genes, which is consistent with the results of previous studies that have found that the activation of SIPK and WIPK by NtMEK2 ${ }^{\mathrm{DD}}$ leads to the induction of $H M G R$ and $P A L$, as well as Osmotin, PR-1a, PR-lb, PR- $2 b$ and $P R-3 b$ in tobacco (Kim and Zhang, 2004; Yang et al., 2001).

Isolation of differentially expressed genes (DEGs) mediated by the NtMEK2 and rice 48-kDa MBP kinase cascade. The ACP-based differential display reverse transcription polymerase chain reaction (DDRT-PCR) technique was used to screen for downstream genes mediated by the NtMEK2 and rice $48-\mathrm{kDa}$ MBP kinase cascade in $N t M E K 2^{D D}$ transgenic rice. The DDRT-PCR technique uses special primers that are designed to specifically anneal only to the template, thereby ensuring that only genuine products are amplified and eliminating false-positive products (Hwang et al., 2003; Kim et al., 2004). Two DEGs were identified in the total RNA of $N t M E K 2^{D D}$ transgenic rice plants using 20 arbitrary ACP primers. Sequence analysis of the PCR

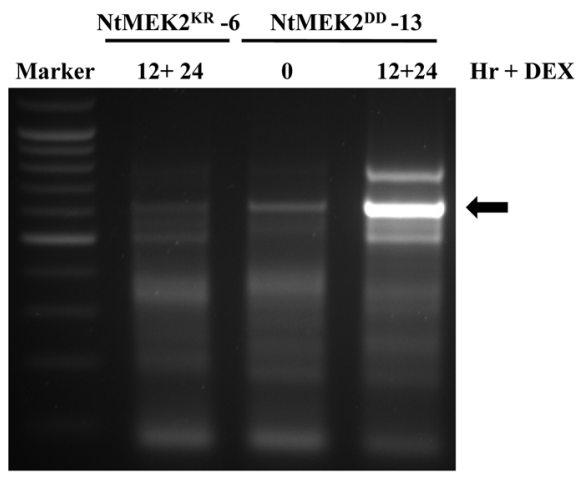

(B)

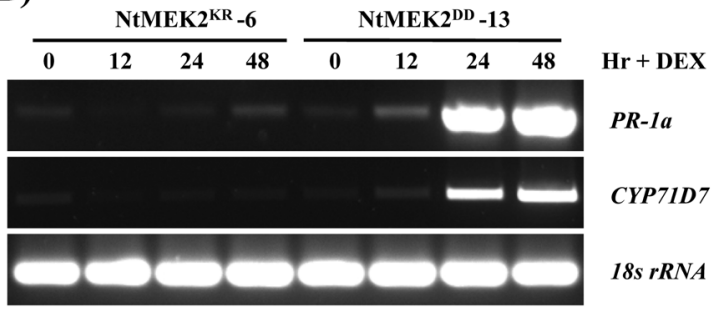

Fig. 5. ACP-based DDRT-PCR and RT-PCR analysis in both $N t M E K 2^{K R}$ and $N t M E K 2^{D D}$ transgenic rice plants. (A) Representative band patterns for differential expression between $N t M E K 2^{K R}$ 6 and $N t M E K 2^{D D}-13$ transgenic rice after ACP-based DDRT-PCR analysis. Arrow indicates a cDNA fragment that was identified as acidic pathogenesis-related protein 1 (PR-1a, Accession No. AF251277) through sequencing analysis. (B) Reverse transcription-PCR analysis of differentially expressed genes (DEGs) in $N t M E K 2^{K R}$ and $N t M E K 2^{D D}$ transgenic rice were treated with DEX $(100 \mu \mathrm{M})$. The same total RNA used in Fig. 4 was used for the analyses shown here. The amplified cDNA products were separated on $1.5 \%$ agarose gels and stained with EtBr. The experiment was repeated three times with similar results. products conducted using the basic local alignment search tool (BLAST) revealed that these 2 DEGs were involved in the plant defense response. Figure 5A shows the differentially expressed cDNA band, which was identified as acidic pathogenesis-related protein 1 (PR-1a, Accession No. AF251277). A putative CYP71D7 that showed high homology to the elicitor-inducible cytochrome P450, CYP71D20 of tobacco (70\%) was also obtained using these techniques (Accession No. AK065971). RT-PCR analysis confirmed that these two DEGs were up-regulated in $N t M E K 2^{D D}$ transgenic rice when compared to NtMEK2 $2^{K R}$ transgenic rice (Fig. 5B). Expression of the $P R-1 a$ gene is induced by infection with the rice blight fungus, Magnaporthe grisea, or the bacterial leaf blight pathogen, Xoo, and in response to treatment with chemical SAR inducer such as BTH, which suggests that PR-1a plays an important role in rice defense responses (Kim et al., 2001). However, the signal pathway associated with activation of the $P R-1 a$ gene is still unknown. Our results suggest that rice $48-\mathrm{kDa}$ MBP kinase regulates the expression of $P R$ genes, including the PR-1a gene (Fig. 4 and 5B). Cytochrome $\mathrm{P} 450$ are heme-thiolate protein products belonging to a very large gene superfamily that includes 272 genes in Arabidopsis and 457 genes in rice that play key roles in the metabolism of physiologically important compounds such as defense compounds (isoflavonoids, phytoalexins, hydroxamic acids), signaling molecules (SA and JA), fatty acids and structural polymers (lignins) (Ehlting et al., 2006; Li et al., 2007; Xu et al., 2001). The tobacco CYP71D mRNA was found to be rapidly induced in cells that were treated with a fungal elicitor, reaching its maximum expression 6 to $9 \mathrm{~h}$ after treatment. In addition, the CYP71D20-encoded

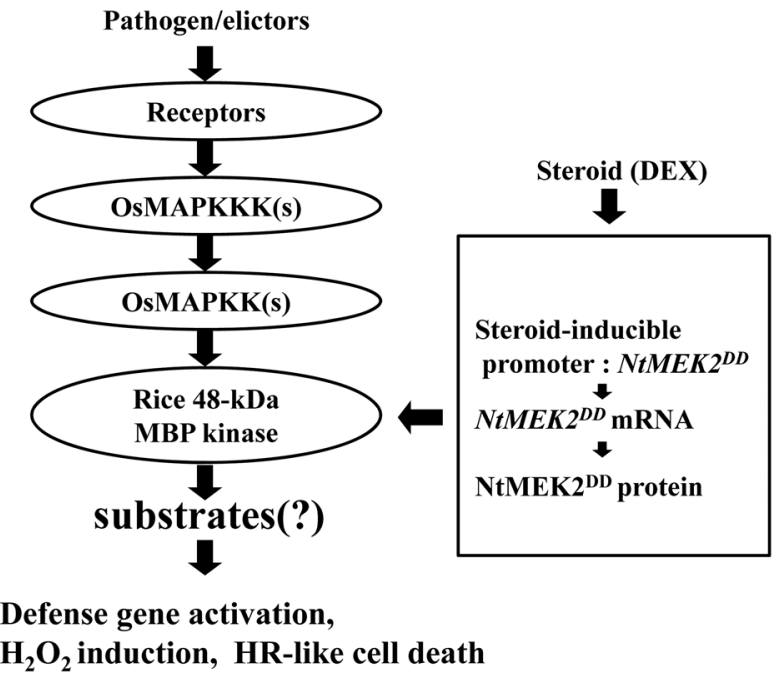

Fig. 6. A model depicting the tobacco MAPK kinase, NtMEK2, which functionally activates the rice endogenous $48-\mathrm{kDa} \mathrm{MBP}$ kinase and leads to downstream defense responses in rice. 
enzyme was found to be involved in the production of capsidiol in vitro, which is a dihydroxylated sesquiterpene produced by several solanaceous species (Ralston et al., 2001). Furthermore, a fungal-responsive MAPK cascade that plays a positive role in regulation of the biosynthesis of phytoalexin via up-regulation of multiple genes in the camalexin biosynthetic pathway involved in cytochrome P450 enzymes such as CYP79B2, CYP71A13 and CYP71B15 in Arabidopsis has also been identified (Ren et al., 2008). These findings suggest that rice 48-kDa MBP kinase regulates the expression of putative CYP71D7 genes involved in the defense response in rice.

In summary, the results of this study demonstrate that NtMEK2 can be used to replace rice MAPK kinase to activate the downstream MAPK pathway involved in multiple defense responses in rice (Fig. 6). In addition, the results of this study indicate that NtMEK2 transgenic rice plants will be a useful tool for the identification of downstream defense genes regulated by the rice 48-kDa MBP kinase, which will aid in the study of disease resistance in rice.

\section{Acknowledgments}

This work was supported in part by a grant from the Technology Development Program of the Ministry of Agriculture and Forestry, and a grant (R11-2001-092-02006-0) from the KOSEF through the APSRC at CNU, and the KOSEF-JSPS Scientific Cooperation Program (F01-2005000-10108-0) funded by KOSEF.

\section{References}

Asai, T., Tena, G., Plotnikova, J., Willmann, M. R., Chi, W. L., Gomez-Gomez, L., Boller, T., Ausubel, F. M. and Sheen, J. 2002. MAP kinase signalling cascade in Arabidopsis innate immunity. Nature 415:977-983.

Ehlting, J., Provart, N. J. and Werck-Reichhart, D. 2006. Functional annotation of the Arabidopsis P450 superfamily based on large-scale co-expression analysis. Biochem. Soc. Trans. 34:1192-1198.

Hiei, Y., Ohta, S., Komari, T. and Kumashiro, T. 1994. Efficient transformation of rice (Oryza sativa L.) mediated by Agrobacterium and sequence analysis of the boundaries of the T-DNA. Plant J. 6:271-282.

Hwang, I. T., Kim, Y. J., Kim, S. H., Kwak, C. I., Gu, Y. Y. and Chun, J. Y. 2003. Annealing control primer system for improving specificity of PCR amplification. BioTechniques 35:1180-1184.

Jin, H., Liu, Y., Yang, K. Y., Kim, C. Y., Baker, B. and Zhang, S. 2003. Function of a mitogen-activated protein kinase pathway in $N$ gene-mediated resistance in tobacco. Plant J. 33:719-731.

Jonak, C., Okresz, L., Bogre, L. and Hirt, H. 2002. Complexity, cross talk and integration of plant MAP kinase signaling. Curr.
Opin. Plant Biol. 5:415-424.

Kachroo, A., He, Z., Patkar, R., Zhu, Q., Zhong, J., Li, D., Ronald, P., Lamb, C. and Chattoo, B. B. 2003. Induction of $\mathrm{H}_{2} \mathrm{O}_{2}$ in transgenic rice leads to cell death and enhanced resistance to both bacterial and fungal pathogens. Transgenic Res. 12:577586.

Katou, S., Yamamoto, A., Yoshioka, H., Kawakita, K. and Doke, N. 2003. Functional analysis of potato mitogen-activated protein kinase kinase, StMEK1. J. Gen. Plant Pathol. 69:161168.

Kauffman, H. E., Reddy, A. P. K., Hsieh, S. P. Y. and Merca, S. D. 1973. An improved technique for evaluating resistance of rice varieties to Xanthomonas oryzae (bacterial blight). Plant Dis. Rep. 57:537-541.

Kim, C. Y. and Zhang, S. 2004. Activation of a mitogen-activated protein kinase cascade induces WRKY family of transcription factors and defense genes in tobacco. Plant J. 38:142-151.

Kim, S., Ahn, I. P., Park, C. H., Park, S. G., Park, S. Y., Jwa, N. S. and Lee, Y. H. 2001. Molecular characterization of the cDNA encoding an acidic isoform of PR-1 protein in rice. Mol. Cells 11:115-121.

Kim, Y. J., Kwak, C. I., Gu, Y. Y., Hwang, I. T. and Chun, J. Y. 2004. Annealing control primer system for identification of differentially expressed genes on agarose gels. BioTechniques 36:424-434.

Kottapalli, K. R., Rakwal, R., Satoh, K., Shibato, J., Kottapalli, P., Iwahashi, H. and Kikuchi, S. 2007. Transcriptional profiling of indica rice cultivar IET8585 (Ajaya) infected with bacterial leaf blight pathogen Xanthomonas oryzae pv. oryzae. Plant Physiol. Biochem. 45:834-850.

Lee, K., Jeon, H. and Kim, M. 2002. Optimization of a mature embryo-based in vitro culture system for high-frequency somatic embryogenic callus induction and plant regeneration from japonica rice cultivars. Plant Cell, Tiss. Org. Cult. 71:237-244.

Lee, M. O., Cho, K., Kim, S. H., Jeong, S. H., Kim, J. A., Jung, Y. H., Shim, J., Shibato, J., Rakwal, R., Tamogami, S., Kubo, A., Agrawal, G. K. and Jwa, N. S. 2008. Novel rice OSSIPK is a multiple stress responsive MAPK family member showing rhythmic expression at mRNA level. Planta 227:981-990.

Li, L., Cheng, H., Gai, J. and Yu, D. 2007. Genome-wide identification and characterization of putative cytochrome P450 genes in the model legume Medicago truncatula. Planta 226:109-123.

Lieberherr, D., Thao, N. P., Nakashima, A., Umemura, K., Kawasaki, T. and Shimamoto, K. 2005. A sphingolipid elicitor-inducible mitogen-activated protein kinase is regulated by the small GTPase OsRacl and heterotrimetric G-protein in rice. Plant Physiol. 138:1644-1652.

Liu, Y., Jin, H., Yang, K. Y., Kim, C. Y., Baker, B. and Zhang, S. 2003. Interaction between two mitogen-activated protein kinases during tobacco defense signaling. Plant J.34:149-160.

Liu, Y., Ren, D., Pike, S., Pallardy, S., Gassmann, W. and Zhang, S. 2007. Chloroplast-generated reactive oxygen species are involved in hypersensitive response-like cell death mediated by a mitogen-activated protein kinase cascade. Plant $J$. 
51:941-954.

Ichimura, K., Shinozaki, K., Tena, G., Sheen, J., Henny, Y., Champion, A., Kreis, M., Zhang, S. and Hirt, H. 2002. Mitogen-activated protein kinase cascades in plants: a new nomenclature. Trends Plant Sci. 7:301-308.

Mishra, N. S., Tuteja, R. and Tuteja, N. 2006. Signaling through MAP kinase networks in plants. Arch. Biochem Biophys. 452:55-68.

Ouwerkerk, P. B. F., De Kam, R. J., Hoge, J. H. C. and Meijer, A. H. 2001. Glucocorticoid-inducible gene expression in rice. Planta 213:370-378.

Ralston, L., Kwon, S. T., Schoenbeck, M., Ralston, J., Schenk, D. J., Coates, R. M. and Chappell, J. 2001. Cloning, heterologous expression, and functional characterization of 5-epi-aristolochene-1,3-dihydroxylase from tobacco (Nicotiana tabacum). Arch. Biochem. Biophys. 393:222-235.

Ren, D., Yang, H. and Zhang, S. 2002. Cell Death Mediated by MAPK Is Associated with Hydrogen Peroxide Production in Arabidopsis. J. Biol. Chem. 277:559-565.

Ren, D., Liu, Y., Yang, K. Y., Han, L., Mao, G., Glazebrook, J. and Zhang, S. 2008. A fungal-responsive MAPK cascade regulates phytoalexin biosynthesis in Arabidopsis. Proc. Natl. Acad. Sci. USA 105:5638-5643.

Rohila, J. S. and Yang, Y. 2007. Rice mitogen-activated protein kinase gene family and its role in biotic and abiotic stress response. J. Integrative Plant Biol. 49:751-759.

Thordal-Christensen, H., Zhang, Z., Wei, Y. and Collinge, D. B. 1997. Subcellular localization of $\mathrm{H}_{2} \mathrm{O}_{2}$ in plants. $\mathrm{H}_{2} \mathrm{O}_{2}$ accumu- lation in papillae and hypersensitive response during the barley-powdery mildew interaction. Plant J. 11:1187-1194.

Widmann, C., Gibson, S., Jarpe, M. B. and Johnson, G. L. 1999. Mitogen-activated protein kinase: conservation of a threekinase module from yeast to human. Physiol. Rev. 79:143-180.

Xu, W., Bak, S., Decker, A., Paquette, S. M., Feyereisen, R. and Galbraith, D. W. 2001. Microarray-based analysis of gene expression in very large gene families: the cytochrome P450 gene superfamily of Arabidopsis thaliana. Gene 272:61-74.

Yamamizo, C., Kuchimura, K., Kobayashi, A., Katou, S., Kawakita, K., Jones, J. D., Doke, N. and Yoshioka, H. 2006. Rewiring mitogen-activated protein kinase cascade by positive feedback confers potato blight resistance. Plant Physiol. 140:681-692.

Yang, K. Y., Liu, Y. and Zhang, S. 2001. Activation of a mitogenactivated protein kinase pathway is involved in disease resistance in tobacco. Proc. Natl. Acad. Sci. USA 98:741-746.

Zhang, S. and Klessig, D. F. 1998. Resistance gene $N$-mediated de novo synthesis and activation of a tobacco mitogen-activated protein kinase by tobacco mosaic virus infection. Proc. Natl. Acad. Sci. USA 95:7433-7438.

Zhang, S. and Klessig, D. F. 2001. MAPK cascades in plant defense signaling. Trends Plant Sci. 6:520-527.

Zhang, S. and Liu, Y. 2001. Activation of salicylic acid-induced protein kinase, a mitogen-activated protein kinase, induces multiple defense responses in tobacco. Plant Cell 13:18771889. 